\title{
A synthetic biology approach allows inducible retrotransposition in whole plants
}

\author{
Gudrun Böhmdorfer • Andrea Tramontano • \\ Kerstin Luxa $\cdot$ Andreas Bachmair
}

Received: 22 December 2009/Revised: 20 February 2010/ Accepted: 22 February 2010/Published online: 11 March 2010

(C) The Author(s) 2010. This article is published with open access at Springerlink.com

\begin{abstract}
Retrotransposons are mobile genetic elements that transpose by reverse transcription of element RNA, followed by insertion of the cDNA into new positions of the host genome. Although they are major constituents of eukaryotic genomes, many facets of their biology remain to be understood. Transposition is generally rare, suggesting that it is subject to tight regulation. However, only the first regulatory step (transcriptional induction) is currently amenable to investigation in higher eukaryotes. To investigate the complete life cycle of a long terminal repeat (LTR) retrotransposon in plants, we established a synthetic biology program on tobacco retrotransposon Tto1, and achieved transposition in whole plants triggered by an inducible promoter. The engineered element, iTto (inducible Tto1), is a novel tool for analysis of retrotransposition in plants. In addition, it allows to explore the potential of an inducible retrotransposon for insertional mutagenesis.
\end{abstract}

Electronic supplementary material The online version of this article (doi:10.1007/s11693-010-9053-4) contains supplementary material, which is available to authorized users.

G. Böhmdorfer · A. Tramontano · K. Luxa · A. Bachmair

Max Planck Institute for Plant Breeding Research,

Carl-von-Linné-Weg 10, 50829 Cologne, Germany

G. Böhmdorfer

Gregor Mendel Institute of Molecular Plant Biology,

Dr. Bohr-Gasse 3, 1030 Vienna, Austria

A. Tramontano $\cdot$ A. Bachmair $(\bowtie)$

Department of Biochemistry and Cell Biology, Max F. Perutz

Laboratories, University of Vienna, Dr. Bohr-Gasse 9,

1030 Vienna, Austria

e-mail: andreas.bachmair@univie.ac.at
Keywords Retrotransposon - Inducible promoter . Arabidopsis thaliana $\cdot$ Plants $\cdot$ Tto1 .

Transposon mutagenesis

\section{Introduction}

Retroelements are abundant components of eukaryotic genomes, and their activity impacts on genome evolution (Bennetzen 2005; Boeke and Stoye 1997; Brookfield 2005; Feschotte et al. 2002; Symer and Boeke 2010). Progress in understanding the natural history of retroelements has been made by analysis of whole genome sequences. However, analysis of host factors and element properties relevant to their transposition characteristics is still lagging behind. Reasons for this are rooted in the generally rare occurrence of transposition events. Another difficulty arises from the repetitive nature of most retroelements, which usually occur in families of dozens to millions of related elements with highly similar, but often not identical sequence. The repetitive nature makes it difficult to establish structurefunction relationships, because different members may contribute differentially to the overall activity of the family.

Retrotransposition is controlled by small RNAs, with element copy number as an important quantitative determinant of repression (Cheng et al. 2006; Jensen et al. 1999; Jordan and Miller 2009; Pérez-Hormache et al. 2008). In the plants Arabidopsis thaliana and in rice, mutants with lesions in either RNA-based defense systems, or in DNA/chromatin-based gene silencing mechanisms, show higher transposition frequency of endogenous elements (Ding et al. 2007; Mirouze et al. 2009; Miura et al. 2001; Tsukahara et al. 2009). Besides small RNA-based control, activity of plant retrotransposons is determined by promoter 
characteristics. All plant retrotransposons investigated so far have stress-inducible promoters, linking mRNA production to stress conditions. In plants with wild type genetic background, heritable transposition during the normal life cycle is usually negligible. In contrast, cell culture conditions can effectively stimulate transposition, resulting in induction of retrotransposon promoters and overriding the RNA-mediated repression. However, the transcriptional profile and thus the properties of cultured plant cells differ significantly from differentiated tissues. It is therefore unclear to which extent tissue culture induction can serve as a model for the transposition events detected by genome-wide comparison of related plant lines. Moreover, tissue culture induction has so far not been used for a dissection of the retrotransposon life cycle.

It is currently unclear whether the low activity of retrotransposons in wild type plants is solely due to the restricted activity of retroelement promoters (Mhiri et al. 1997; Takeda et al. 1998), or whether additional factors such as poor access of integration complexes to wild type chromatin represent another bottleneck.

We have adopted a synthetic biology approach to promote the functional analysis of LTR retrotransposon Tto1, and the adaptation of this element for insertion mutagenesis. Firstly, we introduce a single copy of Tto1 into a heterologous plant species, to reduce repeat-induced silencing processes that normally act to repress activity. Secondly, we have equipped the element with an inducible promoter, allowing induction of element activity at an experimenter's discretion in defined transgenic plant lines. Thirdly, the engineered element contains introns to facilitate detection of transposed copies. We have previously shown that such a system allows generation of cDNA copies of the element (Böhmdorfer et al. 2008). However, it was previously unclear whether these manipulations also provide conditions where the complete life cycle, including cDNA integration, can be observed in whole plants. In this work, we show that inducible retrotransposition with reasonable frequency can be achieved using an engineered retrotransposon, iTto, in whole plants with wild type genetic background. This finding opens the way for further investigation of the transposition process, and for exploration of iTto as an insertional mutagen, in absence of inducing tissue culture conditions.

\section{Materials and methods}

DNA constructs

Vector pBTto3.I. (Böhmdorfer et al. 2008) was digested with Sma I and Xho I, and the ensuing Ttol containing fragment was inserted into vector pER8 (Zuo et al. 2000) that had previously been digested with Spe I, treated with Klenow fragment of $E$. coli DNA polymerase I and digested with Xho I to give plasmid pERnewTto, the vector encoding iTto. A schematic drawing of the transferred DNA of pERnewTto, as well as the sequence of this vector, are presented in Supplementary Fig. 1.

Plant DNA preparation and analysis

DNA for PCR reactions was prepared as described (Böhmdorfer et al. 2005). Diagnostic PCR reaction to assess presence of intron 1 used primer pair AGC TCG AAG AGT TGT ATG CCT CT/CCG ACA ACT GGT CGA CAA TCC CTT. Diagnostic PCR reaction to assess presence of intron 2 used primer pair GGT GGA AAG AGA GAC TGG TAA/CCC GTA ATT GAT CAT AAG AGA. For DNA gel blot and cloning, plant tissue was ground using a SamplePrep Freezer/Mill 6870 (SPEX). DNA was extracted using the illustra DNA extraction kit PHYTOPURE (GE Healthcare) as recommended by the manufacturer. DNA was digested with Eco RI (Roche) and subjected to DNA gel blot analysis as described (Böhmdorfer et al. 2005). To isolate DNA regions flanking Tto1 insertions, DNA was digested with Eco RI and Hin dIII and separated on an agarose gel. Size fractions of 500-1000 bp and of 1000-2000 bp were eluted from the gel using Wizard SV Gel and PCR Clean-Up System (Promega). The fractions were ligated to Eco RI and Hin dIII (Roche) digested vector Bluescript $\mathrm{SK}+$ and used to transform E. coli strain Stbl4 (Invitrogen). Colony hybridization was carried out using published methods (Ausubel et al. 1987). Positive clones were sequenced, and sequence information abutting the Tto1 insert was used to design PCR primers for amplification of the second Tto1-genome junction. Primer pairs ATG TCG GAT TTG GTT ATT GCA CTC/ GAA ATG GAA GGG GGT ATT TAT AGT T, and CCC TCG AGG CAC CTA TTT GGC ACC T/GAA ATG GAA GGG GGT ATT TAT AGT T were used for this purpose, and PCR fragments were directly subjected to sequencing.

Plant handling and treatment

Plants were grown under standard greenhouse conditions (16 h light per day). Accession Col-0 was used to obtain transgenic lines by floral dip transformation (Clough and Bent 1998). For germination of seeds in liquid medium, half strength Gamborg's B5 medium (Duchefa) was supplemented with vitamins, Hygromycin (20 mg/l; Roche) and $\beta$-estradiol ( $5 \mu \mathrm{M}$; Sigma) in Erlenmeyer flasks (100-300 seeds per $100 \mathrm{ml}$ medium) at $23^{\circ} \mathrm{C}$ under gentle agitation $(50 \mathrm{rpm})$ and standard illumination. 


\section{Results and discussion}

Engineering of retrotransposon Tto1

Tto1 from tobacco (Nicotiana tabacum; Hirochika 1993) belongs to the long terminal repeat (LTR) containing retrotransposons. There are ca. 30 copies in the native host, so that any sequence with significant stretches of homology to Tto1 is a likely target for homology-dependent silencing mechanisms in tobacco (Matzke and Birchler 2005; Jordan and Miller 2009; Tijsterman et al. 2002). Due to the lack of homologous sequences, a single copy of Tto1 may not provoke this reaction when introduced into another plant species. However, extra-chromosomal copies (intermediates of transposition) may also be problematic in this respect. We therefore adopted the strategy to put Tto1 under control of an inducible promoter, which is active only after external addition of a small molecule inducer.

We had previously linked modified versions of Tto1 to the dexamethasone-inducible promoter of vector pTA7002 (Aoyama and Chua 1997; Böhmdorfer et al. 2008). However, while the induction strength of pTA7002 is excellent, several publications reported adverse effects of this vector on plant growth (Andersen et al. 2003; Kang et al. 1999; Ouwerkerk et al. 2001). Because of similar experience in our case, we made a new inducible vector based on a $\beta$-estradiol-inducible promoter (vector pER8; Zuo et al. 2000). While the strength of this latter promoter is apparently weaker than that of pTA7002, no toxic side effects are known. The engineered Tto1 element iTto (inducible Tto1) allows formation of a biologically active mRNA molecule upon $\beta$-estradiol induction, similar to the previously reported Tto1 expression under control of a constitutive CaMV35S promoter (Böhmdorfer et al. 2005), or the dexamethasone-inducible expression (Böhmdorfer et al. 2008). iTto contains two introns from A. thaliana, which are spliced efficiently (Fig. 1). At the $3^{\prime}$ end, transcriptional termination sequences of the pea $\mathrm{RbcS}$ gene follow the Tto1 sequences. Analysis of transcripts in A. thaliana suggested, however, that earlier transcription termination signals in the LTR are used predominantly (Böhmdorfer et al. 2005). The mechanism of reverse transcription dictates that transposed copies originating from iTto are identical to the natural tobacco element Tto1: Splicing prior to reverse transcription removes introns, and a full length LTR sequence replaces the inducible promoter through the reverse transcription process (Boeke and Stoye 1997; Fig. 1).

iTto induction results in integration of cDNA copies

Previous experiments had shown that transcription of Tto 1 with the help of an inducible promoter can give rise to (a) Inducible Tto1 (iTto) present on T-DNA

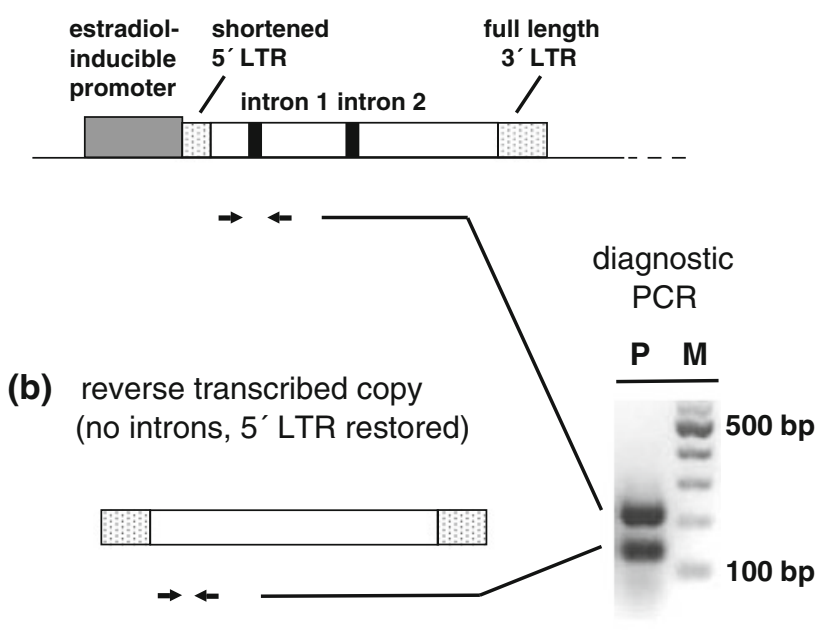

(c) plant genotyping by diagnostic PCR

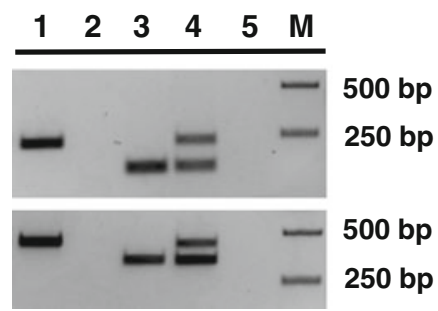

intron 1 PCR

intron 2 PCR

Fig. 1 Retrotransposon Tto1 contains two long terminal repeats (LTRs) that flank a central open reading frame, encoding proteins necessary for transposition. Engineered element iTto as present in T-DNA vector pERnewTto (a) has a $\beta$-estradiol-inducible promoter to replace the promoter of the $5^{\prime}$ LTR, and contains two introns (black boxes). Promoter sequences and introns are not transmitted to reverse transcribed copies (b), which allows to distinguish master copy from reverse transcripts. P, DNA from $\beta$-estradiol-induced plants was used as template for PCR. M, DNA size marker (100 bp steps). c The diagnostic PCR reaction allows for fast genotyping of plants. Lane 1, DNA from transgenic iTto line (no induction); lane 2, DNA from untransformed Col-0 plant; lane 3, DNA from plant with transposition event after outcrossing of the iTto master copy; lane 4, DNA from induced plant with iTto transgene; lane 5, negative control without DNA. M, molecular weight marker bands on agarose gel (size indicated to the right). The pattern of lane 4 does not allow to distinguish between extrachromosomal cDNA and newly integrated copies, whereas the pattern of lane 3 is indicative of Tto1 cDNA copies integrated into the genome

extra-chromosomal full length cDNA in plant tissue (Böhmdorfer et al. 2008). We thus searched for conditions that would allow heritable transposition, i.e. integration of cDNA into the host's germ line. We used the newly constructed vector pERnewTto and capitalized on iTto induction in the shoot (apical) meristem, because this tissue with stem-cell function gives rise to both somatic tissue and to gametes. To optimally expose the apical meristem to the chemical $\beta$-estradiol, A. thaliana seeds were germinated in liquid culture medium containing this chemical. 
After 2 weeks, germinated seedlings were transferred to soil for further growth in absence of the inducer $\beta$-estradiol (Fig. 2). A significant fraction of seedlings transferred from liquid medium to soil developed into mature plants. The absence of $\beta$-estradiol after transfer resulted in iTto shutoff with concomitant cessation of cDNA production. As a consequence, the extra-chromosomal Tto1 cDNA synthesized in induced seedlings is diluted by cell divisions. In contrast, Tto1 copies integrated into chromosomes of meristem cells can be transmitted to somatic progeny tissue and to seeds.

Cauline leaves from plants approaching maturity were used to detect transposition events, using a diagnostic PCR reaction (Figs. 1, 2). From ca. 70 plants tested, three contained strong signals indicative of Tto1 cDNA. As shown below, these plants produced progeny with new Tto1 insertions. We think that the number of plants with transposition events in progeny may actually be higher, because only one leaf per plant was tested. Assuming that the apical meristem contains a minimum of two genetically effective cells (Rédei and Koncz 1992), the number of plants with
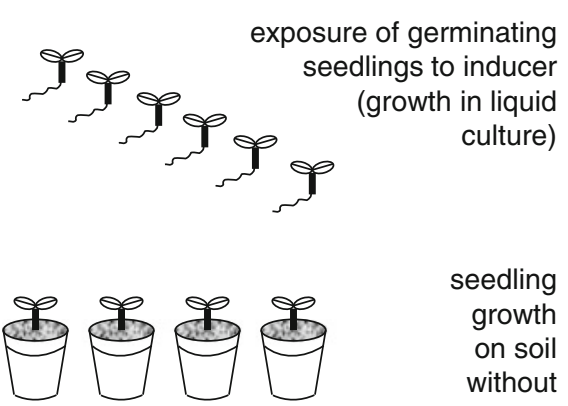

$$
\begin{array}{r}
\text { seedling } \\
\text { growth } \\
\text { on soil } \\
\text { without } \\
\text { inducer }
\end{array}
$$

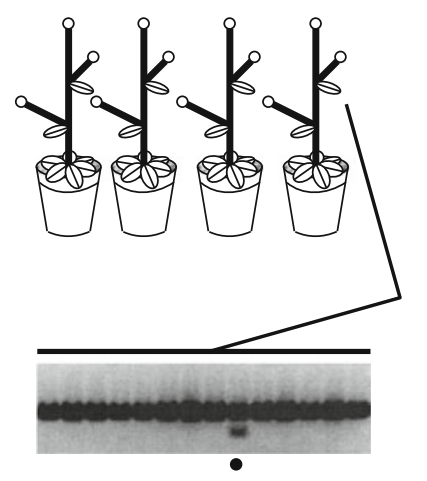

growth to maturity without inducer

\section{diagnostic PCR with \\ DNA from cauline leaves}

plants with diagnostic band (dot) selected for tests in next generation

Fig. 2 Induction of iTto for transposition by treatment of plants with chemical inducer $\beta$-estradiol. Seeds containing iTto were germinated in liquid medium in presence of the inducer. After ca. 2 weeks, seedling growth was continued on soil without inducer. Cauline leaves of mature plants were used for diagnostic PCR reaction (bottom). Presence of Tto1 cDNA (intron absent, lower band, cf. Fig. 1) suggested integration of Ttol cDNA in one of the plants (dot) transposition events in progeny would be twice as high, and will be correspondingly higher if the meristem consists of more cells at the time of transposition. Progeny from candidate plants was re-screened by PCR, and crossed to Col-0 plants devoid of the iTto donor construct. As a further proof of new integration events, we analyzed progeny form the cross by DNA gel blot analysis. Figure 3a shows a blot with DNA from progeny of the outcross (lanes 3-6), together with the original iTto line (lane 1) and untransformed Col-0 plants (lane 2). The probe used detects fragments consisting of the Tto1 $3^{\prime}$ end together with bordering genomic sequences. Thus, different insertions result in different fragment sizes. Due to crossing and segregation, the band indicative of iTto is absent from some plants (lanes 3-5). Both lines presented in Fig. 3 contain more than one new Tto1 insertion. This result suggests that either pre-selection of candidate plants by

(a)

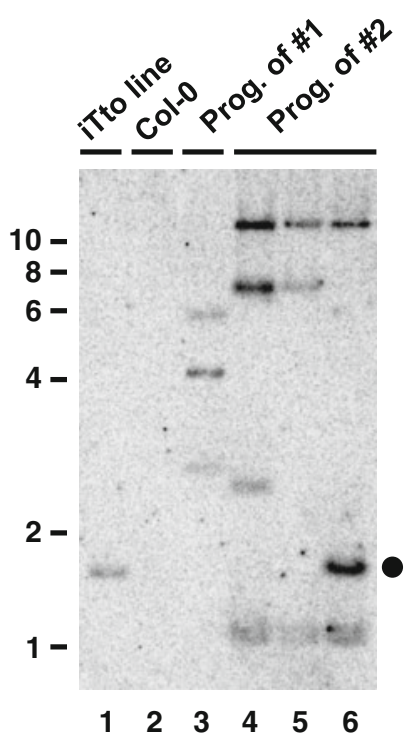

(b)

. . GTCATGGAGGTAGA ( Tto ) GTAGAGGCATCA. . .

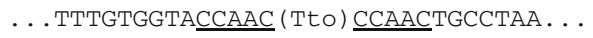

Fig. 3 Characterization of plants with novel Tto1 insertions. a Progeny (Prog.) of two plants with diagnostic PCR band (cf. Figs. 1, 2) were analyzed by DNA isolation, digestion with Eco RI and hybridization to a Tto1 probe. Visualized fragments contain a Tto1 segment and chromosomal DNA flanking the insertion site. A dot indicates the iTto fragment of the progenitor line (lane 1). It is still present in one of the progeny (lane 6), but absent from untransformed Col-0 and from the segregated progeny shown in lanes 3-5. Lanes 3-6 reveal multiple Tto1 insertions. b Sequence characterization of two Tto1 insertion sites from plants as shown in lanes 4 and 5 . The two inserts are unlinked and suggest a similar insertion preference as previously described after tissue culture induction. Underlined: target site duplications flanking the Tto1 inserts 
diagnostic PCR (Fig. 2) favored plants with multiple insertions (which presumably generate a stronger PCR signal than plants with a single transposition event), or that bursts of insertion are a characteristic of the replication mode of iTto under our experimental conditions. For instance, newly inserted copies may be active until cellular gene silencing mechanisms put a halt to their activity (Pérez-Hormache et al. 2008).

Analysis of iTto insertion sites and estimation of insertion frequency

We characterized two new Tto1 insertions of plant line 2 by sequencing of their flanking genomic regions (Fig. 3b). In both cases, transposition resulted in five base pair target site duplications. One insertion occurred into gene At $3 \mathrm{~g} 14480$, whereas the other insertion is located between annotated genes At2g26410 and At2g26420. These findings suggest for iTto the same preference for insertion into actively transcribed regions as previously reported for transposition of Tto1 in tissue culture (Böhmdorfer et al. 2005; Okamoto and Hirochika 2000).

The data presented suggest that posttranslational steps are identical between unmodified Tto 1 and iTto. While this work capitalized on the technical feasibility of manipulation of a plant retrotransposon, it has already answered an open question. It was previously unclear whether plant retrotransposons can transpose at a detectable frequency in whole plants, or whether transposition is essentially restricted to cellular environments with similarity to tissue culture stress (no such an environment is currently known in whole plants). Comparison to previous experiments (Böhmdorfer et al. 2005) also allows a first quantitative assessment of transposition efficiency of Tto1 in tissue culture versus the apical meristem of whole plants. Previous results indicated that two of thirteen plant lines regenerated from tissue culture displayed transposition events with an engineered element driven by the strong "double 35S" promoter (Böhmdorfer et al. 2005). In this work, we found a minimum of three plants with heritable transposition events among ca. 70 tested plants, after transient induction in whole plants with a considerably weaker inducible promoter (as pointed out above, this number may be a conservative estimate). It therefore appears that transposition in the apical meristem of whole plants is not much less efficient than induction in plant callus material, the difference being less than a factor of 10 .

Summary and potential applications of iTto

In summary, we could show that retrotransposon Tto1 can be engineered to achieve inducible transposition in whole plants, demonstrating that retrotransposons can transpose in whole plants and opening the way for further investigations. In particular, the modified element shall be used to analyze the mechanism of transposition. On the one hand, transposition of elements with modified sequence can be compared to iTto activity, to obtain quantitative data under controlled conditions. On the other hand, iTto can be introduced into mutant genetic backgrounds to probe host factors with potential influence on transposition. For example, defects in DNA methylation and chromatin structure have a positive influence on retrotransposition. It is, however, currently unclear whether this influence is solely exerted by a genomic environment that is more permissive for element transcription, or whether DNA methylation also affects later steps such as cDNA integration. As a second future application, we want to adapt iTto as an insertional mutagenesis tool in plants where mutant generation is currently difficult. Tto1 without modifications was previously shown to be active in dicot and in monocot tissue culture cells (Hirochika et al. 1996; Okamoto and Hirochika 2000). We therefore expect that the host range of iTto includes those plants of the dicot family where Arabidopsis introns are efficiently spliced, and the $\beta$-estradiol inducible transcription system is operable. Preliminary experiments indicate that adaptation of iTto for monocots such as barley is also possible, further increasing the range of potential host species for iTto.

Acknowledgments This work was supported by the German Research Foundation DFG (grant 1158/4-1 to A.B.), and by the Max Planck Society.

Open Access This article is distributed under the terms of the Creative Commons Attribution Noncommercial License which permits any noncommercial use, distribution, and reproduction in any medium, provided the original author(s) and source are credited.

\section{References}

Andersen SU, Cvitanich C, Hougaard BK, Roussis A, Gronlund M, Bodker Jensen D, Frokjaer LA, Ostergaard Jensen E (2003) The glucocorticoid-inducible GVG sytem causes severe growth defects in both root and shoot of the model legume Lotus japonicus. Mol Plant Microbe Interact 16:1069-1076

Aoyama T, Chua N-H (1997) A glucocorticoid-mediated transcriptional induction system in transgenic plants. Plant J 11:605-612

Ausubel FM, Brent R, Kingston RF, Moore DO, Seidman JG, Smith JA, Struhl K (1987) Current protocols in molecular biology. Wiley, New York

Bennetzen JL (2005) Transposable elements, gene creation and genome rearrangement in flowering plants. Curr Opin Genet Dev 15:621-627

Boeke JD, Stoye JP (1997) Retrotransposons, endogenous retroviruses, and the evolution of retroelements. In: Coffin JM, Hughes SH, Temin H (eds) Retroviruses. Cold Spring Harbor Laboratory Press, Plainview, pp 335-435 
Böhmdorfer G, Hofacker IL, Garber K, Jelenic S, Nizhynska V, Hirochika H, Stadler PF, Bachmair A (2005) Unorthodox mRNA start site to extend the highly structured leader of retrotransposon Tto1 mRNA increases transposition rate. RNA 11:1181-1191

Böhmdorfer G, Luxa K, Frosch A, Garber K, Tramontano A, Jelenic S, Weber M, Bachmair A (2008) Virus-like particle formation and translational start site choice of the plant retrotransposon Tto1. Virology 373:437-446

Brookfield JF (2005) The ecology of the genome-mobile DNA elements and their hosts. Nat Rev Genet 6:128-136

Cheng C, Daigen M, Hirochika H (2006) Epigenetic regulation of the rice retrotransposon Tos17. Mol Genet Genomics 276: 378-390

Clough SJ, Bent AF (1998) Floral dip: a simplified method for Agrobacterium-mediated transformation of Arabidopsis thaliana. Plant J 16:735-743

Ding Y, Wang X, Su L, Zhai J, Cao S, Zhang D, Liu C, Bi Y, Qian Q, Cheng Z, Chu C, Cao X (2007) SDG714, a histone H3K9 methyltransferase, is involved in Tos17 DNA methylation and transposition in rice. Plant Cell 19:9-22

Feschotte C, Jiang N, Wessler SR (2002) Plant transposable elements: where genetics meets genomics. Nat Rev Genet 3:329-341

Hirochika H (1993) Activation of tobacco retrotransposons during tissue culture. EMBO J 12:2521-2528

Hirochika H, Otsuki H, Yoshikawa M, Otsuki Y, Sugimoto K, Takeda S (1996) Autonomous transposition of the tobacco retrotransposon Tto1 in rice. Plant Cell 8:725-734

Jensen S, Gassama M-P, Heidmann T (1999) Taming of transposable elements by homology-dependent gene silencing. Nat Genet 21:209-212

Jordan IK, Miller WJ (2009) Genome defense against transposable elements and the origin of regulatory RNA. In: Lankenau D-H, Volff J-N (eds) Transposons and the dynamic genome. Springer, Berlin, pp 77-94

Kang H-G, Fang Y, Singh KB (1999) A glucocorticoid-inducible transcription system causes severe growth defects in Arabidopsis and induces defense-related genes. Plant J 20:127-133

Matzke MA, Birchler JA (2005) RNAi-mediated pathways in the nucleus. Nat Rev Genet 6:24-35
Mhiri C, Morel J-B, Vernhettes S, Casacuberta JM, Lucas H, Grandbastien M-A (1997) The promoter of the tobacco Tnt1 retrotransposon is induced by wounding and by abiotic stress. Plant Mol Biol 33:257-266

Mirouze M, Reinders J, Bucher E, Nishimura T, Schneeberger K, Ossowski S, Cao J, Weigel D, Paszkowski J, Mathieu O (2009) Selective epigenetic control of retrotransposition in Arabidopsis. Nature 461:427-430

Miura A, Yonebayashi S, Watanabe K, Toyma T, Shimada H, Kakutani T (2001) Mobilization of transposons by a mutation abolishing full DNA methylation in Arabidopsis. Nature 411:212-214

Okamoto H, Hirochika H (2000) Efficient insertion mutagenesis of Arabidopsis by tissue culture-induced activation of the tobacco retrotransposon Tto1. Plant J 23:291-304

Ouwerkerk PBF, de Kam RJ, Hoge JHC, Meijer AH (2001) Glucocorticoid-inducible gene expression in rice. Planta 213: 370-378

Pérez-Hormache J, Potet F, Beauclair L, Le Masson I, Courtial B, Bouche N, Lucas H (2008) Invasion of the Arabidopsis genome by the tobacco retrotransposon Tnt 1 is controlled by reversible transcriptional gene silencing. Plant Physiol 147:1264-1278

Rédei GP, Koncz C (1992) Classical mutagenesis. In: Koncz C, Chua N-H, Schell J (eds) Methods in arabidopsis research. World Scientific, Singapore, pp 16-82

Symer DE, Boeke JD (2010) The everasting war dance between retrotransposons and their metazoan hosts. In: Kurth R, Bannert N (eds) Retroviruses. Caister Academic Press, pp 1-33

Takeda S, Sugimoto K, Otsuki H, Hirochika H (1998) Transcriptional activation of the tobacco retrotransposon Tto1 by wounding and methyl jasmonate. Plant Mol Biol 36:365-376

Tijsterman M, Ketting RF, Plasterk RHA (2002) The genetics of RNA silencing. Annu Rev Genet 36:478-491

Tsukahara S, Kobayashi A, Kawabe A, Mathieu O, Miura A, Kakutani T (2009) Bursts of retrotransposition reproduced in Arabidopsis. Nature 461:423-426

Zuo JZ, Niu Q-W, Chua N-H (2000) An estrogen receptor-based transactivator XVE mediates highly inducible gene expression in transgenic plants. Plant J 24:265-273 